\title{
UNDERSTANDING QUALITATIVE CONCEPTIONS OF LIVABILITY: AN INDIAN PERSPECTIVE
}

\author{
Rama U Pandey ${ }^{1}$, Yogesh K Garg ${ }^{2}$, Alka Bharat ${ }^{3}$ \\ ${ }^{1}$ Assistant Professor, School of Planning and Architecture Bhopal, Planning Department, M.P., India, \\ rama.ukp@gmail.com \\ ${ }^{2}$ Professor, Architecture and Planning Department, MANIT Bhopal, M.P., India, yogeshkgarg@gmail.com \\ ${ }^{3}$ Professor, Architecture and Planning Department, MANIT Bhopal, M.P., India, alka_bharat@yahoo.com
}

\begin{abstract}
Livability encompasses numerous factors that depend on locally prevailing economic, social and cultural circumstances and therefore becomes necessary to contextualize livability by enlarging focus beyond generic attributes. Livability now a day is pre-requisite for healthy living coupled with economic and social survival therefore, is very important for improving the quality of life.The aim of this paper is to understand qualitative conceptions of livability in an Indian context. A metropolitan city of India with emerging growth potential for real estate development is selected for the study. Inhabitants of residential areas were asked to freely express their understanding of livability. The observations, comments and statements made by inhabitants were recorded and later transcribed. Care was taken to ensure that, as far as possible, the sense of participants' comments was not altered. A qualitative research approach was used to analyze these responses of inhabitants. An iterative process of data interpretation was undertaken to discern the common factors and important aspects, arising from inhabitant's perceptions of livability. The responses of inhabitants suggest various ways and provide direction for identification of livability attributes that are important in contributing towards livability in Indian perspective. Overall twenty categories of responses were identified as livability attributes which summarizes the conceptions of livability as understood by inhabitants. to define in the limited number of qualitatively different ways, in which people experience, interpret, understand, perceive or conceptualize a phenomenon or certain aspect of reality with a minimum of researcher's interference
\end{abstract}

Index Terms: Conceptions, Inhabitants, Livability, Qualitative and Responses $* * *$

\section{INTRODUCTION}

Livability refers to the state of living environment, which should offer an acceptable quality of life to the residents of a particular locale. Livability depends on the locally prevailing economic, social and cultural conditions. In the US, livability refers to overall 'quality of life' and 'well being', whereas in UK, livability focuses strictly on local environment i.e. cleanliness, safety and greenery [1]. In Indian context the livability differs slightly from concept of developed countries though the essence remains the same. According to Confederation of Indian Industries [2] report "developed countries take certain facilities for granted while having the same facilities becomes an attractive preposition for Indian people. Wheeler [3] argues that the most important element in discussions of liveability is the subjective experience of living in particular places. The perception of local populace about livability is important in identifying key attributes of livability which in turn will be useful in assessing the livability.
The paper explores and understands inhabitants' perception of the livability in Indian context. The objective is to identify livability attributes after thoroughly analyzing the recorded statements and observations made by inhabitants for their understanding of livability. The responses asked are for expressing the desires and expectations to making a residential area a livable habitat.

\subsection{Understanding Livability}

Livability refers to the living conditions of a place and reflects people's perception of the place to be fit for living or not. Though the interpretation of livability varies with time and place but the concept seems to share terms like "quality of life", "well-being" and "life satisfaction" all across [1]. Pacione [4] suggested livability to be a quality that is not an attribute inherent in the environment but is behaviour-related function of the interaction between environmental characteristics and personal characteristics. Veenhoven [5] equated "livability" with "habitability" and 
"quality of life" in the nation. He argued that livability is the degree to which its provisions and requirements fit with the needs and capacities of its citizens.

Australian Bureau of Statistics [6] equates livability to quality of life, which is linked strongly to (sometimes synonymous with) wellbeing and can also be used in a collective sense to describe how well a society satisfies people's wants and needs.

M. van Dorst [7], in his research work on livability reported that the ecosystem of the species called human is the living environment. The quality of the match between people and their living environment is therefore known as livability. He further argues that if the inhabitants can control over their territory that is outdoor spaces, the neighbourhood can than function as an ecosystem that can sustain itself. He had clarified this through different perspectives on the relationship between people and environment as well as by distinguishing the different forms of livability in a neighbourhood. Livability thus denotes the sum total of deliverables available to an individual or set of individuals in a particular location, leading to their contentment in day to day life [8].

\subsection{Need to Explore Conceptions of Livability}

Livability has become a global necessity for health, economic and social survival in agglomerations everywhere [9]. Yuen \& Ooi [10] highlighted that cities around the world are re-examining their urban assets and remaking themselves to enhance competitiveness. Livability and vibrancy of the built environment are discussed increasingly on a global scale. Greater attention is given to quality of life [10]. In the Indian context, owning a house for lower and middle income group households is a high point in their life which comes about after years of wait and curtailing expenses to save for their "dream home" in a livable residential area. It is expected by home buyers that residential area should reflect their lifestyle that they had aspired. Although, norms were already laid down by the government and local bodies for residential development regarding provision of open space, internal roads, building byelaws and social infrastructure but at times they fall well short on measures that are critical in determining the desired livability.

McKinsey Global Institute (MGI) report published in April 2010 mentions that "across all major quality of life indicators, India's cities fall well short of delivering even a basic standard of living for their residents"[11] thus pointing the gravity of the problem in Indian context.

\section{RESEARCH APPROACH}

Livability being a subjective notion, its gamut differs with different economic, social, cultural and local influences thereby governing the inhabitants' impression and perception about livability [8]. Hence, for the purpose, an Indian city representing various facets relating to culture, religion, caste, creed etc. of Indian society was selected where more than 60 percent of households represent middle and lower income groups. Higher income group (HIG), economically weaker section (EWS) and persons below poverty level (BPL) are not considered as livability expectations of HIG class would be more oriented towards intangibles like brand value, status symbol etc where as for EWS and BPL persons, the provision of basic social and physical infrastructure would be good enough for livability.

India is a vast country showcasing social and economic diversity among its states and cities. Therefore, a city representing various facets relating to culture, religion, caste, creed etc. of Indian society was selected to carry out the research work. Based on above considerations Bhopal, the capital city of Madhya Pradesh was selected for the study. Bhopal being centrally located in India is well connected to other major cities through rail, road and air and has been attracting peoples from all parts of India, thereby giving rise to a very cosmopolitan culture. Historically, it has been ruled by both Hindu as well as Muslim rulers, which has only added to its evolution into a very pluralistic society.In recent times, Bhopal has emerged as one of the major cities of India and was a part of Confederation of Indian Industry [2] study, "Livability index 2010: The best cities in India". The CII livability index 2010 was based on objective analysis of data collected for top 37 cities of India. The study was carried out in the city of Bhopal to understand how people perceive livability of residential areas.

A qualitative research approach based on phenomenographic methods was adopted. This approach allows individuals to freely express their understanding of the phenomenon which in the context of this study is livability. Phenomenography is not just concerned only with the phenomena being investigated and the people who are experiencing the phenomena but it is also about the relation between the two, that is, the ways in which people experience or think about the phenomena [12]. Analysis of resident's response would allow for the identification of the range of ways in which residents belonging to a particular group of socio economic class understand livability. These differing experiences, understandings etc are grouped in terms of categories of description, logically related to each other, and forming hierarchies in relation to given criteria.

An introduction to the livability was framed after a brain storming session with academicians to introduce livability phenomenon from an ordinary resident's perspective. 
Thereafter a pilot run of the introduction was carried out soliciting views of few residents to assess their understanding and reaction after listening to it. It also helped understanding likely duration of interaction and fine tune the introduction with respect to understanding of language, technical words etc. Further, in order to have most appropriate responses about interviewees' understanding of livability, it was also felt that they need to be presented with probing questions such as "What do you mean?", "Can you explain that?", "Why do you feel that?", "Can you elaborate it?" and "Please give some examples?". During the pilot run, it was also noticed that interviewee used to discuss various issues with his family members and keen to get opinion of his wife and children. Even family members tried to contribute understanding of livability form their own perspective. For example, housewife elaborated on some livability issues of the residential area those were not emphasized by his husband. Hence it is decided to conduct the interview in groups consisting of 6-8 family members of a residential area. The group is so formed that it should have families with different demographic structure like unmarried persons, young couple family, couple with small kids, couple with teenager kids and Senior citizens, almost representing complete life cycle. Care is taken to include families with housewife and working couple families. It was decided to call the selected group at the home of residential area's secretary / president at around 7:00 PM (considering the working Hrs normally up to 6:00 PM) over a cup of tea for the purpose of interview to make the interaction informal. It was also decided to organize a small discussion to sum up the views of all interviewees. Interaction with interviewee's was carried out in 2 stages. Initially, participant (from this point onwards interviewee is called as participant as it is involved in interview and discussion) was interviewed individually to establish his/her understanding of livability using open ended questions designed to elicit his/her personal experience, understanding and expectation. Later group discussion amongst them was conducted on the various livability issues elaborated by them.

Interviews and discussions were recorded through voice recorder and later transcribed. Care was taken to ensure that, as far as possible, the sense of participants' comments was not altered. Two researchers were involved in the analysis and interpretation of the data in order to maximize the validity and reliability of the results. An iterative process of data interpretation was undertaken to discern the common factors and important aspects, arising from inhabitant's perceptions of livability. The results that emerged from the responses given by participants are likely to be indicative of the attributes which are most important to people in judging livability in an Indian context.

\section{ANALYSIS OF INHABITANTS' RESPONSES}

Responses were collected from thirty-five residential areas, which were developed during different time period across the city of Bhopal. It is based on the assumption that residential areas developed during different time period had acquired different problems and strengths during the process of their development. The oldest residential area selected was about 60 years old and the recent developed residential area was about a year old. In thirty-five residential areas 254 residents were participated. During the first stage of interaction, participants were interviewed individually by the researchers to have a firsthand understanding of phenomenon and to ensure data integrity. Interviewer was as non-intrusive as possible to allow participants the freedom to present their own meanings of livability.

Given the fact that interview was conducted in a nonintrusive and free-wheeling manner, the quality of responses was not uniform and at times lacked completeness as well. However the idea has been to let the participants speak out and it is left for the researchers to draw conclusions directly based on the responses or by trying to read between the lines. The questions were cryptic to allow the participant to express his/her feelings without any biases. Participants were asked about their preference for living in any particular locality provided affordability is not the criteria. And that why they would prefer to live in a particular locality, Further, what in their opinion are the factors that affect livability and what factors of livability in their opinion need to be improved to enhance the livability in their existing residential area. In second stage of the meeting, group discussion among the participants were held to summarize and discuss all the issues raised by them.

Participants' responses were analyzed in terms of their perceptions of livability, their understanding of local livability concerns, and their suggestions for how livability problems should be addressed. In the first phase of analysis, the participant's statements and observations after group discussion were analyzed thoroughly by the researchers to identify categories for grouping the responses. The process is carried out by sequential listening of transcripts of all participants and tabulating their responses under major categories. Tabulation of residential areas is based on the sequence in which interaction with participants of various residential areas was conducted and does not depict ascending or descending order as per their development time. Categories were created as per the sequence in which participants responded. Overall twenty categories were acknowledged through sequential process under which responses are grouped representing the overview of various responses given by participants of 35 selected residential areas. The identified twenty livability attributes are illustrated in Error! Reference source not found. with 
further regrouping of livability attributes to define livability.

Second phase of analysis was carried out to sum up and compile the responses for understanding livability in an Indian context. In this phase, responses were again scrutinized and regrouped to understand livability under six categories as shown in Error! Reference source not found.. During regrouping process professionals and academicians were also invited for not to get biased results. These six categories presented the overall perceptions of the participants about important elements of livability.

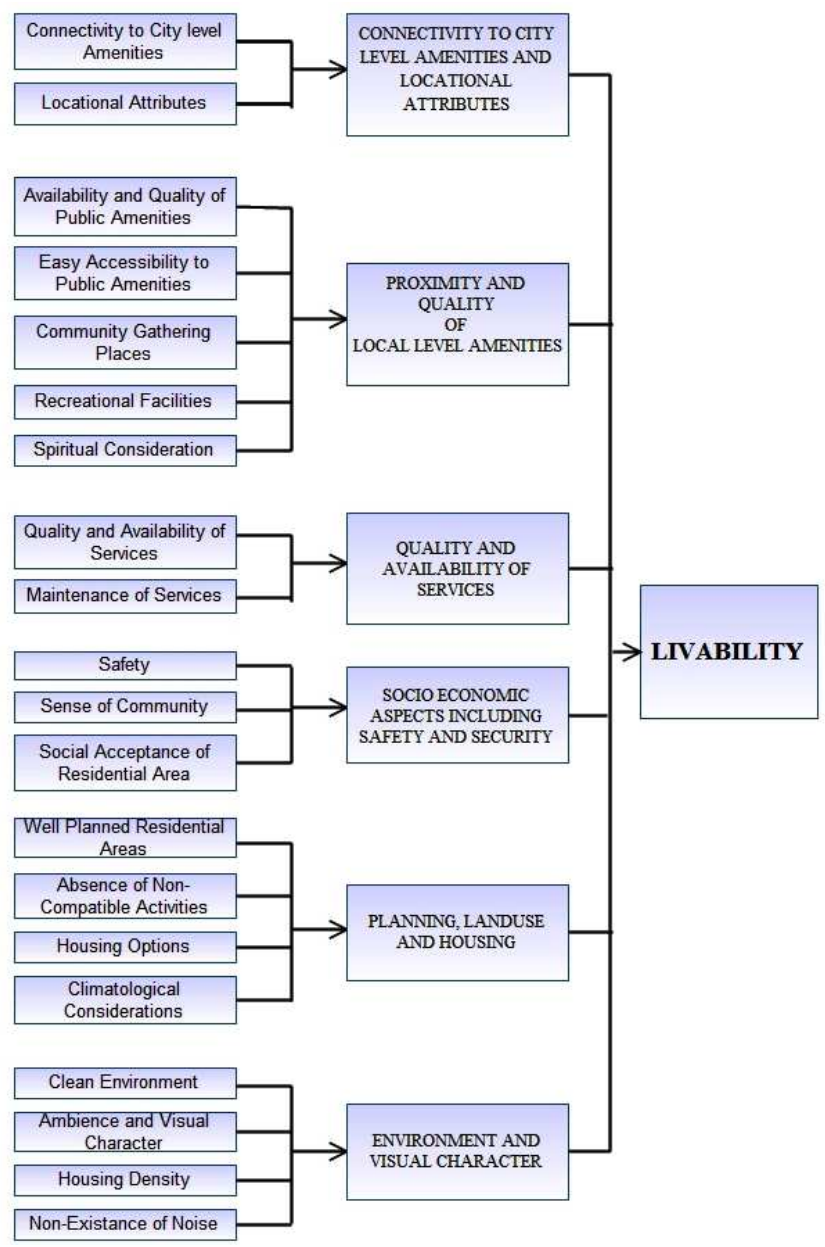

Fig -1: Categorization of identified livability Attributes

\subsection{Connectivity to City Level Amenities and Locational Attributes}

Participants indicated that a number of aspects of connectivity and proximity to city level services were important in their perception of livability. Interaction transcripts show that livability of residential areas encompasses its vital location and connectivity to public transport facilities, hospitals, institutions, local administrative offices and city centre, proximity to work place and easy access for outstation hubs like airport, railway station and bus stand. Many of the respondents, irrespective of the age groups, emphasized upon the importance of location for residential area within the city. Residents, mainly senior citizens, emphasized the importance of proximity to public transport facilities for catering to local travel needs. The participants perceived that for livability connectivity to hospitals too is very important. Many participants also perceived livability of residential area as its location in terms of its distance from their workplace. For few participants' scenic beauty in and around the residential area makes the locality desirable for living.

\subsection{Proximity and Quality of Local Level Public Amenities}

All participants perceived livability as a function of various daily conveniences. This is evident in their responses that they not only desire the requisite amenities at walking distance of maximum 10 minutes but also the quality of amenities and their maintenance too matters in making a place livable. Residents perceived community gathering spaces as one of the factor influencing livability of residential area. This is evidenced by statements relating to the need of gathering spaces for social welfare.

Participants like lady of a house were worried more about the availability of domestic helps in the locality. For persons looking after the household chores, especially when they are working, option of domestic help play an important role in determining the livability of the locality. Many respondents perceived walkways as an integral part of residential areas which in their view needs to be planned along with driveways and complemented with suitable street furniture to encourage interaction among walkers.

\subsection{Quality and availability of infrastructure}

Participants' expect that in a planned residential area, utility services like water supply, electricity and drainage should be as per laid down standards. The quality and availability of well organized physical infrastructure takes care of fifty percent of the livability concerns like adequate, regular and quality water supply, twenty four hours supply of electricity, well designed sewer and surface drainage system that can be maintained with little efforts.

Considering the scarcity of treated water, residents emphasized on provision of rain water harvesting and recycling of waste water for watering landscaped areas along with basic services. In residents' view main approach road to residential areas are to be wide enough to sustain the existing as well as future traffic volume. Hierarchy in road width should be followed to cater to the traffic volume generated within the residential areas. 


\subsection{Socioeconomic Aspects Including Safety and Security}

Participants perceived safety and security as an important factor for livability. In their opinion secured campus is necessary for safety of the residents and should be viewed as a primary requirement for living in harmony with mental peace. It is a prerequisite to enable people, especially senior citizens, to live without any mental worries and keep up with their daily routine.

Respondents' preference to live in localities with likeminded people indicates the strength of community living as it provides psychologically a sense of well being and security. Respondents were apprehensive about encroachment of informal commercial activities and construction activities happening in vicinity. General perception of respondents was that these activities invites nuisance and they don't feel secure. Participants showed their concern for walking comfortably and fearlessly on streets of a residential area.

\subsection{Planning, Land Use and Housing}

The participant's perception of livability of residential areas mainly depended upon housing planning and development. For, housing means not only the shelter for individual or a family but the overall built environment that includes amenities essential for decent living. Foremost concern of residents regarding housing is affordability for the people desirous of living in that location. They emphasized the need for sustainable and energy efficient housing with a variety in typology and designing.

The residents although looked for various options in types/sizes of plot and of flats, but showed their dislike for a mix of extreme specifications i.e. neither big palatial villas nor very small two bedroom row houses. The lifestyle of people somehow decides the scale of tolerance of disorderliness in the outdoor living environment. The participants also commented on how the land use in housing development projects affects the livability. The booming non compatible commercial activities in residential areas are a nuisance. They suggested to segregate commercial and residential land use in a planned way so that the nuisance of commercial activities are kept away from calm and quiet environment of residential use.

\subsection{Environment and Visual Character}

Participants unanimously feel that overall quality of environment with emphasis on overall cleanliness and wide open spaces makes a locality livable. A pollution free environment with proper arrangements for maintaining general cleanliness of locality is a priority for the residents. Scenic ambience and the quality of housing are important for residents to enhance the quality of life. In view of participants area must reflect the lifestyle that they have been aspiring for in their life. Respondents, for a desirable livability showed their concern for housing density. In their view housing density should be optimum, neither too high nor too low. Some of the participants stressed upon the degree of peace and tranquility offered by a place that makes it livable. Many participants highlighted the importance of sense of style and identity, a residential area is associated with. The place where they would like to live must offer them the desired lifestyle.

\section{CONCLUSIONS}

The study has identified twenty livability attributes according to the perception of inhabitants of residential areas in selected city. It has further summarized the livability in six major categories which characterize residents' understanding of livability of residential area and their expectations in Indian context. Out of these six categories one is concerned with connectivity to city level amenities and locational attributes which would facilitate connectivity. Other five categories are related to physical infrastructure and public amenities encompassing: quality and availability of utility services and related infrastructure; local level public amenities; overall quality of environment including the perceptible visual character; planning, housing and land use pattern. Most importantly, participants viewed the satisfaction of their socio-psychological needs viz. safety and security of their lives as well as a sense of community feeling, meeting their social needs, as an important determinant of livability.

Interestingly, some of these categories are seen to be intricately inter- related except for "the connectivity" as it is more concerned with the location of a residential area with respect to ease of accessing major public amenities and services required for living, though not necessarily on a daily basis but occasionally. In Indian context availability and quality of infrastructure, utility services and public amenities along with planning, land use and housing are seen as major contributors in providing the requisite visual character and ambience to a residential area. The provision of utility services and public amenities also has an impact on the perception of safety and security of residents.

The Indians perceived their residential area to be built in a manner where they not only walk comfortably within ten minutes of time but also safely to the local public amenities. For example a grocery store with home delivery services, post office, doctor's clinic, bank, local park, meditation centre within walking distance in or near a residential area, easy accessibility to a weekly vegetable market for fresh vegetables and fruits, easy availability of domestic help for day to day household chores are some of the important criteria for livability. 
Sense of community and safety is much desired for livability which is perceived in Indian perspective through like minded people living together. Encroachment on roads and parks along with disturbing elements like liquor shops, commercial activities are not desired for safety as well as ambience reasons. In India, though the basic amenities and services are available in most of the residential areas but the facilities are not well maintained and lack the quality, which is required to satisfy the desired livability. Residents unanimously emphasized on maintaining quality of amenities and services provided in residential areas. Residents felt that the two aspects one, physical infrastructure and public amenities; second, sociopsychological needs of the residents should be planned in integration for desired livability.

Livability in Indian context can be summarized as ease of mobility that would enable catering to day to day needs, within a span of ten minutes. Emphasis is on qualitative aspects of services and amenities rather than quantitative i.e. counting numbers. For example, quantitatively parks, water supply lines, sewerage lines, storm drainage etc. are generally available but in most of the cases parks are not maintained, they are the places of stray animals, also sometimes used as domestic garbage sites. Sewers are found choked and normally overflow with bad smells. Storm water drains are seldom cleaned and in most of the places found filled up with garbage. Water supply lines are always short of water. Hence livability in Indian context refers to a good quality and well maintained infrastructure and public amenities, a clean and pollution free environment which would also instill a sense of identity, safety and community living amongst residents.

\section{REFERENCES}

[1]. Brook Lyndhurst, Livability \& sustainable development: Bad habits \& hard choices, 2004, Final Report for the UK Office of the Deputy Prime Minister, London, viewed 15 September $2010 . \quad$ website: http://www.communities.gov.uk/documents/corpor ate/pdf/142424.pdf

[2]. Confederation of Indian Industry, 2010, Liveability index 2010: The best cities in India. A CII: Institute for Competitiveness Report, Northern Region, India

[3]. Wheeler, SM, 2001, Livable communities: Creating safe and livable neighborhoods, towns and regions in California: Working Paper 20012004. Berkeley: Institute of Urban and Regional Development, University of California, viewed 10 January 2011, http://wwwiurd.ced.berkeley.edu/pub/WP-2001-04.PDF
[4]. Pacione, M, 1990. Urban liveability: a review. Urban Geogr. 11 (1), 1-30.

[5]. Veenhoven, R, 1999, Quality of life in individualistic society: A comparison of 43 nations in the early 1990s, Social Indicators research, vol $48,157-186$

[6]. Victorian Competition and Efficiency Commission, A state of livability: an inquiry into enhancing Victoria's livability, Final report, State of Victoria, 2008, viewed 7 December 2010,< http://www.vcec.vic.gov.au/CA256EAF001C7B21 /WebObj/VCECLivabilityReportFINALFULLREPORT/\$File/VCEC\%20Livability $\% 20$ Report $\% 20 \% 20$ FINAL\%20FULL\%20REPOR T.pdf

[7]. van Dorst, M, 2012, 'Liveability', in Bueren EV et. al (eds), Sustainable Urban Environments: An Ecosystem Approach, Springer, New York, pp. 223-242.

[8]. Pandey, RU, Garg, YG \& Bharat, A, 2010, A Framework for Evaluating Residential Built Environment Performance for Livability. ITPI Journal 7:4. 12-20.

[9]. Brenner, P \& Brenner, L 2007, livability Planning checklist, Livability Initiative wake up call for Tasmanian urban planning, viewed 10 October 2010 ,

<http://www.livability.info/_docs/Full\%20Livability $\% 20$ Planning\%20Checklist.pdf $>$

[10]. Yeun, B \& Ooi, GL,2009, Introduction: World Cities Challenges of Livability, Sustainability and Vibrancy, Ooi Giok Ling and Belinda Yeun (ed.). World cities : achieving livability and vibrancy. World Scientific Publishing Co. Ltd,Singapore, . 1-12

[11]. McKinsey Global Institute, 2010, India's urban awakening: building inclusive cities, in: Sustaining Economic Growth, McKinsey and Company, 2010

[12]. Marton, F, 1986, Phenomenography - A research approach to investigating different understandings of reality. Journal of Thought 21:3.28-49.

\section{BIOGRAPHIES}

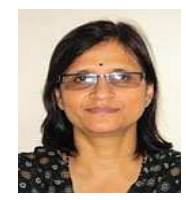

Rama U Pandey, is an Assistant Professor in School of Planning and Architecture Bhopal, has done her B.Arch from MANIT Bhopal, and Post Graduation in Environmental Planning from CEPT Ahmedabad. 
Dr. Yogesh K Garg is a Professor in

MANIT Bhopal, graduated from

MANIT Bhopal, MURP from IIT

Roorkee and $\mathrm{PhD}$ from Barkatullah

1

University Bhopal

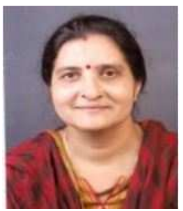

Dr. Alka Bharat is a Professor in

MANIT Bhopal, graduated from

MANIT Bhopal, Post Graduation from

IIT Roorkee and PhD from Barkatullah

University Bhopal 